\title{
Influence of Internal Control on Financial Application System on Procurement Management at SOS Hermann Gmeiner School, Uasin Gishu, Kenya
}

\author{
Faith Muthoni Kibe, Paul Amolloh Odundo \\ Universitity of Nairobi, Nairobi, Kenya
}

\begin{abstract}
Adoption of Internal control on Financial Application Systems (FAS) improves procurement management process by raising efficiency through reduction of pilferages. An institution that has well set internal controls is likely to have benefits brought by transparency, accountability, and usage of available resources. Organizations adopting use of FAS in Internal control (procedural, operating, periodic, and feedback controls) in procurement management enhance transparency, accountability in the procurement process. However, issues arise from non users of FAS in mismanagement of funds reported delay in procurement process. Benefits have not been documented and schools are still susceptible to frauds and malpractices associated with manual functioning of procurement management. The study assessed influence of internal control in Financial Application Systems on procurement management (PM) at SOS Eldoret, Uasin Gishu. The study employed census research design with target population of program director, 10 board management committees, 16 finance officers, and 52 teachers of Hermann Gmeiner School (HGS). The study employed structured questionnaire and interview for data collection. Analysis was obtained through classifying and tabulation of data. Internal control amongst which procedural control had more influence on procurement. Findings revealed that: timelines, planning, pre-qualification, and payment manipulation were curbed in procurement process through use of well set procedures and guidelines. However, operating controls were not adequately utilized in procurement since the institution did not perform fraud risk assessment which only identifies fraud and loss using set controls. Periodic controls in procurement management were found to monitors inventory on periodic basis to ascertain delivery frequency. The study recommends that HGS developed policy on management of internal controls of the FAS to account for procurement processes. Right persons recruited to run the system effectively and efficiently. School management to customize feedback control to enhance monitoring and evaluation of procurement process.
\end{abstract}

Keywords: internal controls, procurement management, operating controls, periodic controls, feedback controls, efficiency and transparency, periodic review control, school management

Faith Muthoni Kibe, master of project planning and management, Department of Educational Communication and Technology, Universitity of Nairobi, Nairobi, Kenya.

Paul Amolloh Odundo, prof., Department of Educational Communication and Technology, Universitity of Nairobi, Nairobi, Kenya.

Correspondence concerning this article should be addressed to Paul Amolloh Odundo, 79162-00400 Tom Mboya Street, Nairobi, Kenya. 


\section{Background of the Study}

Effective internal control in FAS tends to reduce pilferages within procurement management. An institution where internal controls are effective, little or no loss is realized hence enhancing accountability and transparency in procurement process. Organisations are working towards increasing effectiveness, efficiency, and transparency of procurement process. Effective use of set internal control in FAS tends to raise efficiency in procurement process in acquisition of institutional goals. There is need for transparency while enhancing openness and clarity of procurement management policy and system (World Bank, 2003). Ineffective use of internal controls in FAS leads to pilferages, fraud, favoritism in terms of selection of suppliers, misuse of resources, and manipulation of the controls. Internal control in FAS influences procurement management in organizations driven by efficient and effective internal controls set in FAS to improve procurement management process (Mendoza, 2008).

Internal controls in FAS guide information entry, organizations planning, and control processes to ensure reliable procurement functioning by ensuring effective resource allocation in the procurement process (Zima, 2007). Internal control ensures achievement of an organization's objectives using FAS in operational effectiveness and efficiency, reliable financial reporting, and compliance with laws, regulations, and policies (Chenhall, 2013). Internal control, controls risks in an organization (Glance, 2006). An organization's resources are directed, monitored, and measured in order to detect and prevent fraud and protect the organization's resources, physical (machinery and property), and intangible (reputation or intellectual property such as trademarks). At institution level, internal control objectives relate to the reliability of financial reporting, timely feedback on the achievement of operational or strategic goals, and compliance with laws and regulations (Brahim, 2014). At the specific transaction level, internal control refers to the actions taken to achieve a specific objective (how to ensure the organization's payments to the third parties is for valid services rendered). Internal control procedures reduce process variation leading to more predictable outcomes (Chenhall, 2013).

Internal controls in financial application system are customized to suit procurement management process which contains a number of functionalities relating to procurement function. The functions of internal control in FAS are to customize the organizations procurement needs and account for key operations including procedural control, operating control, periodic control, and feedback controls (Knight, 2007). Failure to use internal control would mean benefits that are not accrued by the institution. Procedural control in FAS involves some procedures which are standards and acceptable in an organization. These standards lay basis for purchasing goods and services required in the organization (Verdina, 2011). Procedural controls in financial systems involve step-by-step procedures of inputting data into the system to prevent shortcut procedure and overwriting data. In developing countries, procurement procedures have loopholes which are prone to fraud and theft (Brahim, 2014). These loopholes provide room for incompetent suppliers and contractors to be selected and allowed to participate in the whole process of procuring. However, there are procedural controls which can curb such malpractice in the systems where organizations have incorporated in the financial systems. These controls are set to eliminate or rather follow set of standards to ensure that competent suppliers and contractors are chosen (Glance, 2006).

In procedural control, minimum timelines are laid down regarding publication of notices, invitation to tender, and receipt of document. Setting time limits for receipt of tenders and request to participate, procurement team takes into account the complexity of the contract and timelines required in acquisition of 
goods of services. Timelines can be drawn with responsibilities assigned for each activity within procurement team and suppliers. This approach gives an overall timescale for the process and enables procurement to be managed efficiently and effectively to achieve fast delivery. Planning in procurement using FAS fastens the process of thinking and organizes the activities required to achieve desired goal. It involves the creation of internal controls that guides planning process from end to end, such as psychological aspects that require conceptual skills. (Henderson, 2008).

Pre qualification in FAS uses set internal controls for the purpose of short listing to reduce the number of bidders to be generally three to five. Evaluating bidders is time consuming exercise but with well set internal controls in FAS procurement team that only pick bidders who have qualified and capable meeting their requirement operational control in FAS serve to regulate the day-to-day output relative to schedules, specification, and costs. Operational control includes control over normal business processes that are executed by an organization. Are inventories, goods-in-process, and finished products being purchased and produced in the desired quantities? Are the costs associated with the transformation process in line with cost estimates? Is the information needed in the transformation process available in the right form and at the right time? Is the energy resource being utilized efficiently (Chenhall, 2013)?

Operation controls in financial system play major role in prevention and detection of fraud. Companies are required to perform a fraud risk assessment and assess related controls using operational controls (Glance, 2006). This typically involves identifying scenarios in which thefts or losses occur and determine control procedures effectively managing the risk to an acceptable level. Senior management override financial controls, which leads to manipulation in financial reporting that is key focus in operational control (Vijayakumar \& Nagaraja, 2012). Inventory management using FAS is the process of efficiently overseeing the constant flow of units into and out of an existing inventory. This process usually involves controlling the transfer of units in order to prevent the inventory from becoming high, or dwindling to levels that could put the operation of the institution into jeopardy.

According to Thomson and Jackson (2007), purchase-to-pay (p2p) process consists of many sub-processes from sourcing, ordering, receipting, payment through to contract, and relationship management. Through automation, components of the process can be either removed or deskilled improving efficiency and reducing cost. Technological advances in Enterprise Resource Planning (ERP) and web-based procurement systems have provided the tools for purchasing and supplying management professionals to consolidate information reduce costs and increase service. Purchase-to-pay systems automate the full purchase-to-payment process, connecting procurement, and invoicing operations through an intertwined business flow that automates the process from identification of a need, planning, and budgeting, through to procurement and payment.

FAS uses periodic review control in procurement management to monitor inventory levels on a periodic basis in order to establish a consistent order and delivery frequency with their suppliers. This policy usually requires persons to observe the current inventory level at a consistent point in time ( the end of a work week) and to place an order to return the current inventory position to predetermined order-up-to level (Amudo, 2009). The periodic reviews in relation to financial application system is a process of assessment, monitoring, and reporting on the needs of the suppliers and contractors. The goal of these reviews is to provide objective and credible data that can be used to target assistance and inform future assessments (Reid \& Smith, 2010).

Setting targets and performance measures in FAS are essential for continuous improvement in the procurement process. Complex and high-cost procurement, targets, and performance measures are key element 
of project planning, where strategic requirements are involved. The procurement team should review and refine their targets throughout the procurement process. The procurement team needs to develop range of targets and measures for procurement projects. Monitoring performance is essential in procurement rather than waiting for completion of procurement process; it allows the procurement team to identify areas for improvement and enhance the long-term benefits from the process. The procurement team focuses on performance against specific criteria identified in the business case, supplier performance against milestones or standards, and overall value for money. Internal controls in periodic controls provide with monitoring applications for purchase orders, contracts, and budgets. These enable people to monitor the procurement process and procurement-relevant dates from planning the items to be ordered (Kwanbo, 2009).

According to Ray and Pany (2004), continuous use of FAS in feedback controls in procurement management activities is conceived to have significant influence on operational efficiency by means of cost reduction. These encompass diverse range of policies and procedures that help to ensure management directives that are carried out and ensure that any actions that may be needed to address risks that are taken to achieve company objectives. Further studies of Ray and Pany (2004) pointed control activities as components of financial application controls and considered control activities as policies and procedures that help ensure that management directives are carried out. Controls activities in an organization basically comprise: performance reviews, information processing, physical controls, and segregation of duties. Reid and Smith (2010) posited that control activities need to be funded by the control environment and there should be continuous monitoring and evaluations as well as reviews by way of audit to enforce compliance.

According to Ngugi (2010), control activities are one of the components of internal control whose likelihood of achievement is affected by limitations inherent in all systems of internal control. Control activities are the basis of assurance and are only possible with the establishment of effective internal control system. Kwanbo (2009) posited that weak periodic controls allow or introduce both intentional and unintentional mis-statements into the financial reporting process that leads to lower quality accruals. Periodic control activities occur throughout the organization at all levels and in all functions, it is in small or large companies. Preventive controls are proactive in nature and seek to prevent undesirable events from occurring as well as deter losses and include: separation of duties, proper authorization, adequate documentation, and physical control over assets (Amudo, 2009).

According to Joseph (2010), while developing performance reviews system in FAS, organizations place systems to control the procurement of products and services and the verification of purchased products to satisfy the requirements. Similarly, auditors may consider it is sufficient to confirm compliance by checking that an organization approved supplier list is up to date, that orders have been placed only with those approved suppliers and that activities necessary for meeting specified purchase requirements have been carried out (Vijayakumar \& Nagaraja, 2012). Auditing is a feedback control in FAS, the process used by procurement management, auditors must keep in mind that procurement starts right at the beginning of the process during the design and development of a product when a specification is prepared. The organization should also ensure that the specified purchase requirements are correct prior to their communication to the supplier and that statutory and regulatory requirements have been included in the purchase requirements. The organization should also ensure that the specified purchase requirements are correct prior to their communication to the supplier and that statutory and regulatory requirements have been included in the purchase requirements.

According to Osei-Tutu, Mensah, and Ameyaw (2011), compliance checklists reflect good practice in procurement processes by providing a set of indicators to assess adherence to the institution procurement rules 
and regulations. They are often structured around the major phases of the procurement cycle and typically cover the various risks associated with each phase of the contracting process.

Globally, policies to enhance the usage of Financial Application Systems have been enacted with an aim of ensuring effectiveness of the procurement management (OECD-DAC, 2008). Private sector is often used as a benchmark for efficiency, procurement managements cannot still be said to be efficient (Tadelis, 2012). Transparency and corruption prevention in private sector in the use of procurement funds view the institutionalization of additional controls and checks and balances as limiting to the agility and responsiveness of procurement practices. Procurement management in Africa has been characterized by manual procurement management with few institutions in the continent ready to take up the challenge of automating procurement management. Few organizations in Africa have managed to fully automate their procurement management (Mahmood, 2010). Countries such as South Africa and Nigeria have their public and private institution automates procurement management (World Bank, 2003). This helps in dealing with the malpractices associated with the procurement management and also improves the image and confidence of the organization and that of suppliers respectively (OECD-DAC, 2008).

Procurement in Kenya has undergone series of interesting transformations (Awiti, 2008). Bohnstedt (2008) noted that procurement in the country has evolved from a rudimentary system with no universal control framework to the gradual automation of procurement management in the country (Bohnstedt, 2008). Kenya government has been in the forefront in championing changes in the procurement sector. Consequently, private institutions have borrowed leaf from the public institutions and even adopted some of the regulations provided by the public sector relating to procurement managements (Verdina, 2011). The private sector is in the processes of improving its procurement management as it adopts financial application systems and tightens its procurement regulations (Bohnstedt, 2008).

Locally, schools have adopted the use of Financial Application Systems. The schools' procurement function is guided and controlled by the use of the Financial Application System, however the institution is not protected from the malpractices associated in the procurement department (Ngugi, 2010). The school has made tremendous progress in the management of procurement functions. Institutions face procurement issues despite of using FAS (Chenhall, 2013). This has necessitated the undertaking of this study to clearly assess the best ways in which the Financial Application System can be utilized in the institution to achieve recommendable results in the use of procurement management.

\section{Statement of the Problem}

Procurement management process should be effective, reliable, efficient, and accountable to enable the management to operate with both long and short term goal (Knight, 2007). Effective use of internal control in FAS enhances procurement management as fundamental function institution. Internal control in FAS in organizations has benefited procurement management committees by automating the procurement process hence reducing human fraud and manipulation. However, this is not the case in institutions; Financial Application Systems have been proposed to assist procurement management in organization in private and public sector (PPOA, 2007). FASs have internal controls that provide set guidelines that govern its utilization in procurement process. Procedural control in internal control in FAS involves procedures which are standards and acceptable in an organization. These standards lay the basis for purchasing goods and services required in the organization (Verdina, 2011). Despite having internal control utilization, the Financial Application System 
is experiencing shortcomings in the management of its procurement operations: delays, procurement of low quality products due to poor supplier optimization, and inflexibility in the planning process associated with design FAS.

\section{Purpose of the Study}

The broad objective of this study was to establish influence of internal controls in financial application system on procurement management at Hermann Gmeiner School at SOS Eldoret, Uasin Gishu County, Kenya. The exercise was intended to provide useful information procurement managers of the school and the Procurement Management Team (PMT). Specifically, the study set out to encourage institutions to adopt the use of FAS in procurement proces.

\section{Theoretical Framework}

The study was founded on reliability theory of Gavrilov and Gavrilova (2001). Reliability theory of internal control system comprises of components that are interrelated. Each component of internal control defines measure of success (procedural, operating, periodical, and feedback controls). The reliability of component is defined as the probability of the component success state. The two potential users of the reliability theory are the external auditor and organization procurement management. Reliability theory was used during the external audit, evidence was gathered to support professional opinion.

Theory examines reliability of employed financial application system and extent which system influences procurement management process. The theory analyzes the components of financial systems (procedural, operating, periodic, and feedback control) and specifically the input of data, processing of data, and accuracy of the output in relation to procurement.

\section{Conceptual Framework}

The conceptual framework used in this study helps to explain the influence of internal control (procedural, operating, periodic, and feedback control) in financial application systems on procurement management. Ineffective internal controls can inhibit procurement management in an organization. However, well guidelines in internal control in procurement aim at enhancing transparency, accountability, and reliability to the donor or funding. Effective internal controls in FAS control risk and govern resource utilization.

\section{Research Design}

The study employed case study research to gather data from the teachers, procurement management committee, school directors, and finance officers. The case study research design was preferred because it ensured complete description of the situation, making sure that there were minimal bias in collection of data findings to determine where and how of a phenomenon (Kothari, 2004). The study covered a target population of 94 employees of HGS Eldoret in Uasin Gishu County. The study therefore targeted program director, 10 board management committees, 16 finance officers, and 52 teachers' respondents. Census sampling technique is a procedure of systematically acquiring and recording information about the members of a given population (Ader, 2008). Census sampling technique was used to identify 94 respondents for the study. The instrument for collecting data was questionnaires for teachers and procurement management committee and an interview was conducted to school directors and finance officers. 


\section{Findings and Discussions}

The study sought to establish influence of internal control on procurement management in HGS by finding out how several parameters affect procurement while using FAS. Internal control, procedural control, feedback control, periodic control, and operating controls affect adoption of FAS in procurement.

\section{Sufficiency of Internal Control at Hermann Gmeiner School}

According to Amudo (2009), sufficiency of internal control assesses achievement of setting control in FAS with accordance of organization objective in operational effectiveness and efficiency in terms of reliability financial reporting, timely feedback on achievement of operational or strategic goals, compliance with the law, regulation, and policies in procurement management.

Figure 1 looks at sufficiency of the number of internal control in FAS in the procurement management. A increasing number of internal control using FAS reduces bureaucracies in procurement management. The study therefore sought to establish the sufficiency of internal controls at Hermann Gmeiner School.

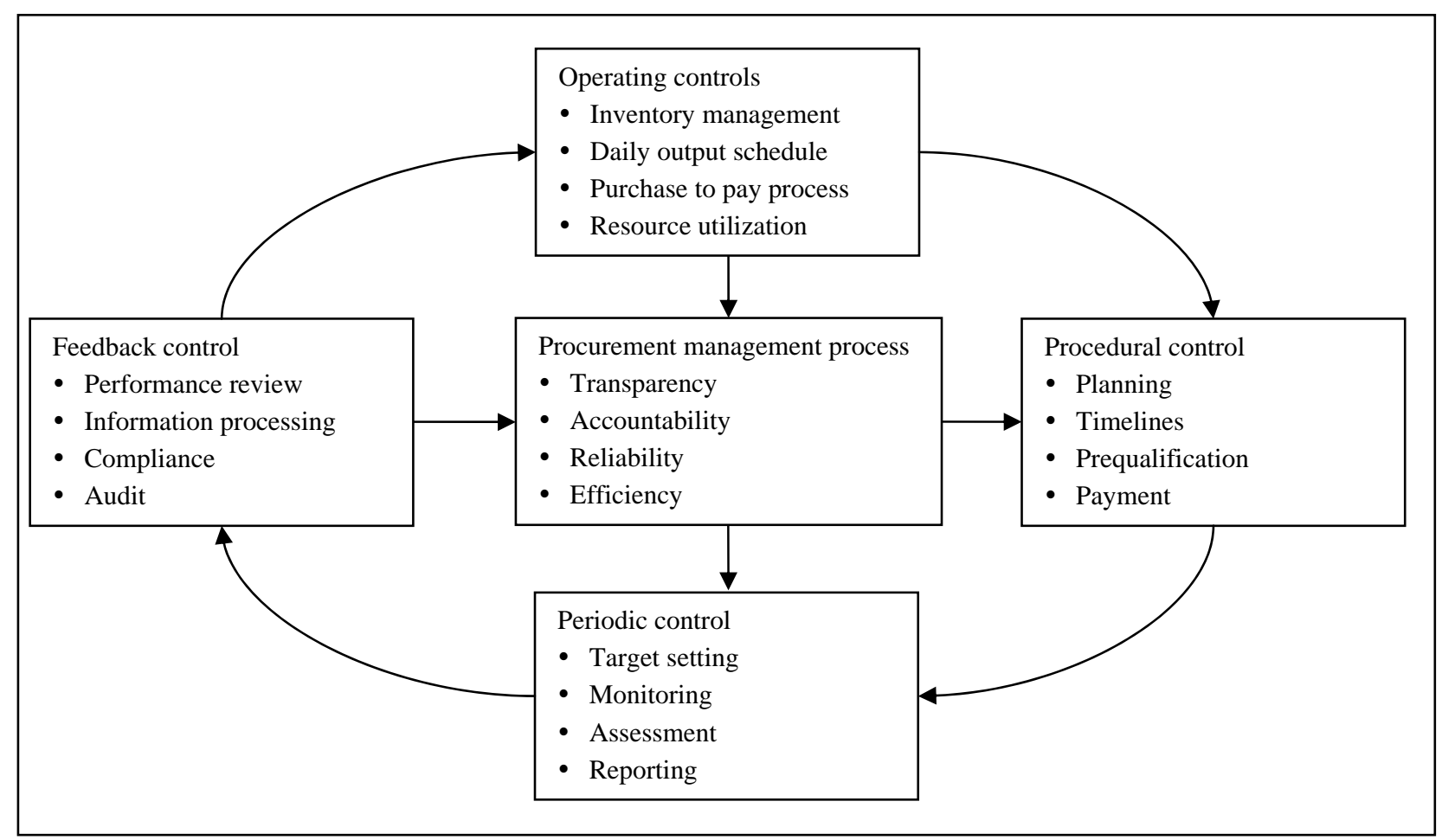

Figure 1. Conceptual framework.

Table 1

Sufficiency of Internal Controls on Hermann Gmeiner School

\begin{tabular}{llll}
\hline Response & & Frequency & Percent \% \\
\hline \multirow{2}{*}{ Yes } & Male & 25 & 45 \\
& Female & 30 & 55 \\
& Total & 55 & 66 \\
\multirow{2}{*}{ No } & Female & 18 & 64 \\
& Male & 10 & 36 \\
\hline
\end{tabular}

Note. $N=83$. 
From Table 1, the study found out that of 55 (66\%) respondents, 25 (45\%) females and 30 (55\%) males opinioned that the school has sufficient internal control; 28 (34\%) of 18 (64\%) of females and 10 (36\%) of males reported that the school has insufficient internal control. The female's comprised majority revealed that the school has insufficient internal control and they felt that most controls do not take into account of a third gender rule while issuing tenders. This implied that male employees who interacted with the FAS system found the system is more secure in terms of managing the schools resources compared to a manual system which is more prone to inefficiencies such as fraud and delays in procurement and management of financial resources.

The respondents further noted that FAS has a number of internal controls but this can be improved to make it more effective for the procurement department. These findings agree with the finding of Brahim (2014) that availability of effective internal controls was necessary for proper procurement management in those organizations. Further, internal control enhances transparency of procurement process by eliminating human manipulation that has personal interest. A control also ensures that procurement plan is followed to the last stage and every error is detected and the system users prompted to repeat the procedure.

Table 2

Operating and Procedural Controls in Internal Controls on Procurement Management

\begin{tabular}{lllllllllll}
\hline & & SD & D & U & A & SA & Total & Mean & SD \\
\hline \multirow{2}{*}{ Operating controls } & $\mathrm{F}$ & 2 & 2 & 22 & 37 & 20 & 83 & 3.86 & 0.90 & 77.1 \\
& $\%$ & 2.4 & 2.4 & 26.5 & 44.6 & 24.1 & 100 & 4.06 & 0.92 \\
\multirow{2}{*}{ Procedural controls } & $\mathrm{F}$ & 1 & 4 & 14 & 34 & 30 & 83 & 41.2 & \\
& $\%$ & 1.2 & 4.8 & 16.9 & 41 & 36.1 & 100 & 81.2 \\
\hline
\end{tabular}

Note. $N=83$.

The findings from Table 2 found that two (2.4\%) out of 83 employees of Hermann Gmeiner strongly disagree that operating control in internal control in FAS on procurement while two (2.4\%) disagree. Additionally, 20 (24.1\%) strongly agree that operating control in internal control influences procurement while 37 (44.6\%) agree. However, 22 (26.5\%) were undecided whether operating controls influence procurement. These findings indicate that the majority of HGS's staff concurred that operating system in internal control influenced procurement. These findings conform with operational controls in FAS which regulate day to day output relative to schedules, specification, and cost in execution of normal business processes.

Cumulatively, one (1.2\%) strongly disagreed that procedural control influences procurement management while four (4.8\%) disagree. Additionally, 14 (16.9\%) were undecided that procedural control influences procurement due to lack of necessary information in procurement process. Further findings showed that 30 (36.1\%) employees strongly agreed that procedural control influences procurement management while 34 (41\%) agreed. These findings indicate that the majority of procurement team in HGS felt that proper procedures and standards which are acceptable in the organization were followed step by step in inputting data into the system. These findings agree with findings of Verdina (2011) that procedural standards lay the basis for purchasing goods and services required in the organization.

The finding from Table 3 depicts that one (1.2\%) out of 83 employees of Hermann Gmeiner strongly disagree that periodic controls influence procurement, while 11 (13.3\%) disagree, the majority being teachers and project managers who stated that while monitoring inventory levels on periodic basis they take longer period as compared to stipulated weekly assessment. Additionally, 18 (21.7\%) were undecided on the effect of 
periodic controls on procurement management due to limited information due to lack of knowledge; 15 (18.1\%) strongly agreed that periodic control influences procurement management while 38 (45.8\%) agreed. These findings indicate that the majority of HGS's staff understand periodic review control in internal control in procurement management used to establish consistent order and delivery frequency with their suppliers. Procurement committee members indicated that inventory is done consistently at the end of work week to determine order up level, they are also used in assessment, monitoring, and reporting to top managers and suppliers. This finding agrees with findings of Reid and Smith (2010) that periodic reviews provide objective and credible data that can be used to target assistance and inform future assessments.

Further finding showed that one (1.2\%) disagreed that feedback controls influence procurement management, while eight (9.6\%) disagreed. Similarly, 25 (30.1\%) were undecided on the effect of feedback controls on procurement management majority being teachers due to their little knowledge on monitoring and evaluation. Additionally, 10 (12\%) strongly agreed that feedback controls influence procurement management while 39 (47\%) agreed. This finding indicated that continuous use of FAS in feedback controls in procurement management activities was conceived by finance officer to have significant influence on operational efficiency hence cost reduces. These studies conform with Keeny and La Fond (2009), who posited that weak periodic controls allow or introduce both intentional and unintentional mis-statements into the financial reporting process that leads to lower quality accruals.

Table 3

Periodic and Feedback Control in Internal Controls on Procurement Management

\begin{tabular}{llllllllll}
\hline & & SD & D & U & A & SA & Total & Mean & SD \\
\hline \multirow{2}{*}{ Periodic controls } & F & 1 & 11 & 18 & 38 & 15 & 83 & 3.66 & 0.97 \\
& $\%$ & 1.2 & 13.3 & 21.7 & 45.8 & 18.1 & 100 & 73.3 & \\
\hline \multirow{2}{*}{ Feedback controls } & $\mathrm{F}$ & 1 & 8 & 25 & 39 & 10 & 83 & 3.59 & 0.87 \\
& $\%$ & 1.2 & 9.6 & 30.1 & 47 & 12 & 100 & 71.8 & \\
\hline
\end{tabular}

Note. $N=83$.

Table 4

Internal Controls on Procurement Management

\begin{tabular}{llllllllll}
\hline & & SD & D & U & A & SA & Total & Mean & SD \\
\hline \multirow{2}{*}{ Operating controls } & $\mathrm{F}$ & 2 & 2 & 22 & 37 & 20 & 83 & 3.86 & 0.90 \\
& $\%$ & 2.4 & 2.4 & 26.5 & 44.6 & 24.1 & 100 & 77.1 & \\
\hline \multirow{2}{*}{ Procedural controls } & $\mathrm{F}$ & 1 & 4 & 14 & 34 & 30 & 83 & 4.06 & 0.92 \\
& $\%$ & 1.2 & 4.8 & 16.9 & 41 & 36.1 & 100 & 81.2 & \\
\hline \multirow{2}{*}{ Periodic controls } & $\mathrm{F}$ & 1 & 11 & 18 & 38 & 15 & 83 & 3.66 & 0.97 \\
& $\%$ & 1.2 & 13.3 & 21.7 & 45.8 & 18.1 & 100 & 73.3 & \\
\hline \multirow{2}{*}{ Feedback controls } & $\mathrm{F}$ & 1 & 8 & 25 & 39 & 10 & 83 & 3.59 & 0.87 \\
& $\%$ & 1.2 & 9.6 & 30.1 & 47 & 12 & 100 & 71.8 & \\
\hline
\end{tabular}

Note. $N=83$.

From Table 4, the study found out that of $83(100 \%)$ respondents $81.2 \%$ (mean $=4.06)$ revealed that procedural controls affect procurement management while $77.1 \%$ (mean $=3.86$ ) stated that operating controls affect procurement management; 73.3\% (mean $=3.66$ ) of respondents noted that periodic controls have an effect, while $71.8 \%$ (mean $=3.59$ ) of respondents agreed that feedback controls affect procurement management. 
The study also found out that procedural controls have more influence on procurement management. This finding implies that well set procedures and guidelines do not allow any manipulation of such processes by influential people or procurement personnel whose intention is to have personal gain or favor some bids. However, procedural controls allow thorough selection of competent suppliers and contractors who have the capacity to provide a particular service or supplier.

This study agrees with the findings conducted by Boulemia (2014) and was in line with these findings that procedural controls are very significant in the way a contract that is awarded during tendering. He further noted that to a large extent, the regulation of the procurement process is designed to prevent manipulation by bureaucrat through which strict procedural rules can be used to align the interests of the regulator and the public agent, thus limiting favoritism and corruption.

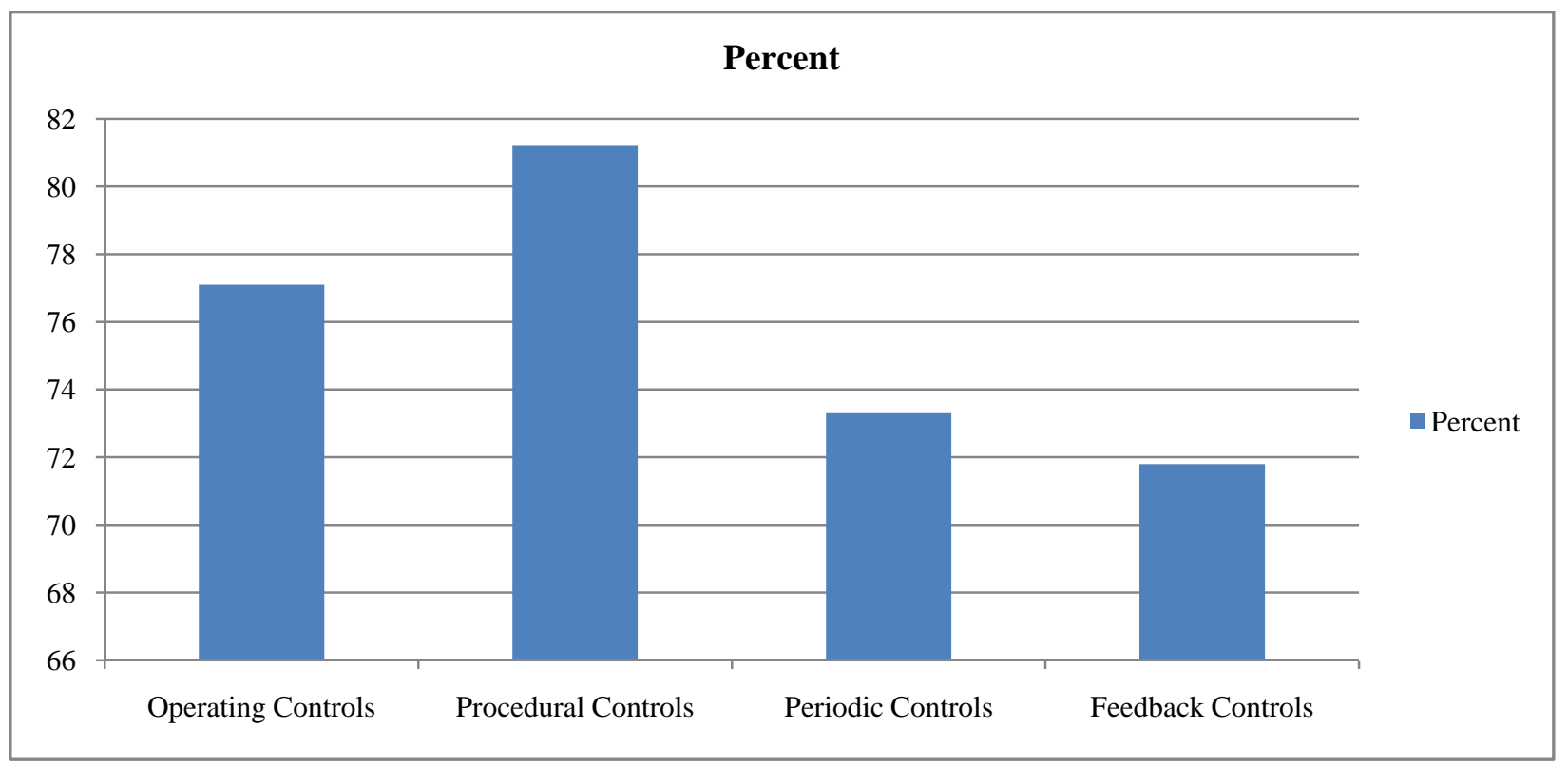

Figure 2. Influence of internal control in financial application system on procurement management.

From Figure 2, the study found that $77.1 \%$ operating controls, procedural control $81.2 \%$, and periodic control 73.3\%, while 71.8\% feedback control in internal control influence procurement management. These findings imply that procedural control and operating controls in internal control influence more on procurement management.

\section{Conclusions}

The study investigated the influence of internal control in financial application system on procurement. Internal controls have great influence on procurement management process. Internal controls integrated in FAS enhance procurement management in several ways. The role of procedural, periodic, operational, and feedback controls in FAS is to make the whole process of management of procurement effective and reliable. The literature review identified trends concerning procurement management as procedural, operational, periodic, and feedback controls. It also identified internal control (procedural, operating, periodic, and feedback controls) amongst which procedural control had more influence on procurement. With well set procedures and guidelines namely: timelines, planning, pre-qualification, and payment do not allow manipulation of the process. 
Operating control, periodic and feedback controls are part of internal controls that facilitate procurement management, however, operating controls could not be adequately used in procurement because organizations are required to perform fraud risk assessment which only identifies fraud and loss that occur up to certain level. Periodic controls in procurement management monitor inventory levels on a periodic basis in order to ascertain delivery frequency with suppliers.

\section{Recommendations}

Based on the conclusion, the researcher made the following recommendations:

1. Hermann Gmeiner School develops policy to continuously customize its FAS application to suite its main operational processes related to procurement management. Persistent fraud and mismanagement of fund can be curbed through customizing FAS to suit procurement management needs.

2. Project managers with the help of procurement committee develop a policy on procurement in FAS on procurement to counter pilferages, fraud, and favourism in terms of selection of suppliers and manipulating the process can be overcome by use of set guidelines (internal controls) in performing all procurement processes.

3. Right persons should be recruited and selected to run the system in the most effective manner in a way that it will achieve the best results for the organization. Avoiding recruiting unqualified person to run FAS, hence, proper recruitment process is to be put across.

4. Financial application system in procurement should be more adopted in organization, so the government mitigates mismanagement of funds to prevent malpractices that may occur, organization/government should develop internal control in FAS that suits needs.

5. Adherence to legislation, policy, and practice in procurement management is due to manipulation of set/laid procedures in internal control in procurement, therefore policies should put in place and well documented.

\section{References}

Ader, H. J. (2008). Phases and initial steps in data analysis (10th ed.). Nairobi: Macmillan Publishers.

Amudo, A. (2009). Evaluation of internal control systems. A case study from Uganda. International Research Journal of Finance and Economics, 3, 124-144.

Awiti, V. P. (2008). An assessment of the use and management of development funds. The case of SME firm in Kenya. Unpublished Masters Report.

Bohnstedt, A. (2008). Procurement and supply in Kenya. The market for small and medium. Macmillan Publishers.

Boulemia, A. (2014). Procedural rules and their impact on procurement outcomes. Evidence from France. Chaire Economie des Partenariats Public-Privé, EPPP DP No. 2014-10.

Brahim, J. (2014). Implementation of procurement planning in parastatal organizations: A case study of Tanzania Postal Bank Head Quarters in Dar-es-salaam. International Journal of Academic Research in Management (IJARM), 3(3), $226-232$.

Chenhall, R. H. (2013). Management control systems design within its organizational context: Findings from contingency-based research and directions for the future. Accounting Organizations and Society, 28, 127-168.

Gavrilov, L. A., \& Gavrilova, N. S (2001). The reliability theory of aging and longevity. J. Theory. Biol., 213(4), 527-545.

Glance, A. (2006). Effectiveness of internal control. Local government. Results of the 2006-2007 Audits, 19-26.

Henderson, J. C. (2008). Strategic alignment: Leveraging information technology for transforming organizations. IBM Systems Journal, 32(1), 4-16.

Joseph, W. B. (2010). The past performance handbook: Applying commercial practices to federal procurement (2nd ed.). Publisher Management Concept Press.

Keeny \& La Fond. (2009). Policy, manage \& economic studies of science. Technology \& Innovations: Research Policy.

Kothari, C. R. (2004). Research methodology method \& techniques (2nd ed.). New Age International. 
Kwanbo, M. L. (2009). Internal control system and the issues of independence and confidentiality in local government auditing: An examination.

Mahmood, S. A. I. (2010). Public procurement and corruption in Bangladesh. Confronting the country challenges and opportunities. Journal of Public Administration and Policy Research, 2(6), 103-111.

Mendoza, O., (2008). Procurement-Challenges facing procurement organizations. Knowledge Wharton: Biomed Central Ltd, Mexico.

Ngugi, H. (2010). Internal factors affecting procurement management of supplies in the public sector. Nairobi: Macmillan publisher.

OECD-DAC, Zambia National Tender Board. OECD-DAC JV. (2007). For procurement pilot programme Zambia: Assessment of public procurement system.

Osei-Tutu, E., Mensah, S., \& Ameyaw, C. (2011). The level of compliance with the public procurement Act 290.

PPOA. (2007). Assesment of the procurement system in Kenya public procurement oversight Authority Nairobi Kenya.

Ray, O., \& Pany, K. (2004). Principles of auditing and other assurance service. McGraw-Hill/Lrwin.

Reid, G. C., \& Smith, J. A. (2010). The impact of contingencies on management accounting system development. Management Accounting Research, 11, 427-450.

Tadelis, S. (2012). Public procurement design: Lessons from the private sector. International Journal of Industrial Organization, 30(3), 297-302.

Thomson, J., \& Jackson, T. (2007). Sustainable procurement in practice: Lessons from local government. Journal of Environmental Planning and Management, 50(3), 421-444.

Verdina, G. (2011). Risk management as a tool for securing internal control in the process of study program implementation at higher education institutions. Economics and Management, 16, 987-991.

Vijayakumar, A. N., \& Nagaraja, N. (2012). Internal control systems: Effectiveness of internal audit in risk management at public sector enterprises. BVIMR Management Edge, 5(1), 1-8.

World Bank. (2003). Policy review. The World Bank procedures \& procedures (68446).

Zima, V. (2007). What is theory? Cultural theory as discourse and dialogue. London. 